\title{
Porous texture evolution in Nomex-derived activated carbon fibers
}

(Journal of Colloid and Interface Science 253, 169-176, 2002)

\author{
S. Villar-Rodil ${ }^{\mathrm{a}}$, , R. Denoyel ${ }^{\mathrm{a}}$, J. Rouquerol ${ }^{\mathrm{a}}$, A. Martínez-Alonso ${ }^{\mathrm{b}}$ and J.M.D. Tascón ${ }^{\mathrm{b}}$ \\ ${ }^{a}$ MADIREL (CNRS-Université de Provence), Site CTM, 26 rue du 141ème RIA, \\ 13331 Marseille, Cedex 3, France. \\ ${ }^{b}$ Instituto Nacional del Carbón, CSIC, Apartado 73, 33080 Oviedo, Spain.
}

\begin{abstract}
In the present work, the textural evolution of a series of activated carbon fibers with increasing burn-off degree, prepared by the pyrolysis and steam activation of Nomex aramid fibers, is followed by measurements of physical adsorption of $\mathrm{N}_{2}(77 \mathrm{~K})$ and $\mathrm{CO}_{2}$ (273 K) and immersion calorimetry into different liquids (dichloromethane, benzene, cyclohexane). The immersion calorimetry results are discussed in depth, paying special attention to the choice of the reference material. The activated carbon fibers studied possess an essentially homogeneous microporous texture, which suggests that these materials may be applied in gas separation, either directly or with additional CVD treatment.
\end{abstract}

Keywords: Activated carbon; Adsorption, Microcalorimetry; Immersion enthalpy, Microporosity.

\section{Introduction}

Due to their excellent adsorption properties, activated carbons play an outstanding role in many areas of modern science and technology, such as separation, purification and 
catalysis $(1,2)$. In recent years, novel fibrous adsorbents known as activated carbon fibers (ACFs) have been developed by the pyrolysis and activation of organic fibers. ACFs have a number of advantages over the conventional activated granular/powdered carbons: high adsorption rates and capacity, a more homogeneous porous system which gives them greater adsorption selectivity, the possibility of their being molded into different shapes, etc.

In recent years, attempts have been made to obtain ACFs with novel porous texture characteristics. Thus, Freeman el al $(3,4)$ first reported on the outstanding homogeneity in pore size of ACFs prepared from highly ordered polymers, such as aramid fibers. Indeed, ACFs prepared from aramid show a narrower pore size distribution than those reported in the literature (5) for ACFs derived from more disordered precursors.

The high price of some aramid fibers prevents them from being used as feedstocks for obtaining carbonaceous adsorbents. However, previous works from one of the authors' laboratories $(6,7)$ have shown that low value by-products from the manufacture of aramid fibers can be an alternative option for the production of low cost ACFs. In addition, activated carbon yields are relatively high for these materials (8-10), so the process could be economically viable if the final adsorbents do offer advantages over the traditional ones. The textural properties of ACFs obtained through physical activation with carbon dioxide and steam using several varieties of aramid fibers as feedstocks have already been reported in the literature (4-7,11-13). However, little attention has been paid to the analysis of their pore size distribution. Moreover, to the authors' knowledge, no low relative pressure $\mathrm{N}_{2}$ adsorption data on this type of materials has yet been reported. Obviously, a proper characterization of the porosity of these adsorbents is essential for their successful synthesis and application. 
In this work, pyrolysis and physical activation with steam were carried out, using Nomex as starting material. Nomex (poly ( $m$-phenylene isophthalamide)) is a particularly attractive precursor for obtaining very selective adsorbents, as it has been proved to yield fibrous adsorbents, whose porosity covers a narrow range in relation to other aramid fibers, making them promising molecular sieves $(4,7,14)$. As for the use of steam as activating agent, it has been suggested that its utilization instead of carbon dioxide in the activation process of aramid fibers does not lead to a significant widening of the pore sizes (4), unlike the case of other carbonaceous materials $(15,16)$. In these conditions, steam is preferable to carbon dioxide from a practical point of view, due to its lower price and its higher reactivity towards carbon (lower temperatures can therefore be used for convenient activation rates, with the subsequent saving of energy).

The textural characterization of the samples has been focused in this work on the determination of their pore size distribution. With this aim, low relative pressure $\mathrm{N}_{2}(77 \mathrm{~K})$ as well as $\mathrm{CO}_{2}(273 \mathrm{~K})$ adsorption isotherms were measured in an attempt to elucidate pore size distributions indirectly by means of different calculation methods. Moreover, immersion calorimetry using adsorptive molecules of different size as molecular probes was employed to obtain a direct measurement of the amount of pores of different sizes. This technique has proved to be a useful tool for the characterization of microporous solids $(16,17)$.

It is expected that these studies will help to predict in which separation processes these materials may be useful and whether it will be necessary to modify their textural characteristics with further treatments such as carbon chemical vapor deposition or other techniques to obtain valuable molecular sieve carbons. 


\section{Materials}

The starting material was commercially available Nomex aramid fiber in a variety known as Crystalline Nomex (T450 2.2 dtex.). All treatments were carried out in a tubular quartz reactor. Batches of about $10 \mathrm{~g}$ of Nomex as received were pyrolyzed in argon (99.99990\% pure by volume, flow rate: $50 \mathrm{~cm}^{3} \mathrm{~min}^{-1}$ ) up to $1073 \mathrm{~K}$ (heating rate: $10 \mathrm{~K}$ $\left.\mathrm{min}^{-1}\right)$ and then cooled down to $1053 \mathrm{~K}$ and activated with a steam/argon mixture $\left(720 \mathrm{~cm}^{-}\right.$ ${ }^{3} \mathrm{~min}^{-1} / 50 \mathrm{~cm}^{-3} \mathrm{~min}^{-1}$ ) for various periods of time to attain different burn-offs (BO), namely, 0, 10, 21, 42 and $63 \%$.

\section{Methods}

Adsorption isotherms of $\mathrm{N}_{2}(77 \mathrm{~K})$ and $\mathrm{CO}_{2}(273 \mathrm{~K})$ were assessed in a Micromeritics ASAP 2010 and a Quantachrome NOVA 1200 volumetric adsorption analyzer, respectively. With the help of a ASAP 2010 apparatus, it is possible to measure $\mathrm{N}_{2}$ adsorption isotherms starting from relative pressures around $10^{-6}-10^{-7}$, in order to obtain so-called "high resolution" $\mathrm{N}_{2}$ adsorption isotherms. Samples were outgassed overnight under vacuum at $523 \mathrm{~K}$ prior to every adsorption experiment.

The heats of immersion of the samples into liquids with different minimal molecular dimensions such as dichloromethane $(0.33 \mathrm{~nm})$, benzene $(0.37 \mathrm{~nm})$ and cyclohexane $(0.48$ $\mathrm{nm}$ ) were determined at $298 \mathrm{~K}$ with a Tian-Calvet differential microcalorimeter (Setaram, Model C80D). The samples ( 0.1 g) were outgassed overnight under vacuum at $523 \mathrm{~K}$. The experimental procedure to determine enthalpies of immersion has been described elsewhere (18).

The densities employed for adsorbed $\mathrm{N}_{2}(77 \mathrm{~K})$ and $\mathrm{CO}_{2}(273 \mathrm{~K})$ were 0.813 (bulk liquid) and $1.182 \mathrm{~g} \mathrm{~cm}^{-3}$ (solid phase) (19), respectively. BET surface areas, $S_{B E T}$, were 
obtained by the standard BET method in the relative pressure range from $10^{-6}$ to 0.1 (20). Total porosity $\left(V_{p(N 2)}\right)$ was calculated from the gas volume adsorbed at $P / P^{0}=0.95$.

Further insight into the textural evolution of the samples was gained through high resolution $\alpha_{S}$-analysis, based on the original $\alpha_{S} \square$ method proposed by Gregg and Sing (21a) and reviewed for the high resolution adsorption isotherms by Kaneko (22). In this procedure, the adsorption isotherm for a given porous solid is expressed as a function of the amount adsorbed on a macroporous or non porous reference adsorbent. To do this, a parameter $\left(\alpha_{S}\right)$ is defined as the ratio of the amount adsorbed on the reference solid at each equilibrium relative pressure to the amount adsorbed at the relative pressure ( 0.4 for nitrogen) at which all the micropores are supposed to be already filled and the adsorbed amount is plotted as a function of $\alpha_{S}$. External surface areas $\left(S_{\text {ext }(\alpha s, N 2)}\right)$ are calculated from the slope of the linear segment of the $\alpha_{s}$ plot corresponding to $\alpha_{S}$ higher than 1 . Total micropore volumes $\left(V_{\mu p(\alpha s, N 2)}\right)$ as well as ultramicropore volumes $\left(V_{u \mu p(\alpha s, N 2)}\right)$ are obtained from the $y$-axis intercepts of the linear portions of the $\alpha_{S}$ plots corresponding respectively to the highest $\alpha_{S}$ values and to $\alpha_{S}$ of around 0.5. Spheron 6 carbon black $\left(S_{B E T}=108 \mathrm{~m}^{2} \mathrm{~g}^{-1}\right)$, which has been shown to be equivalent to other reference materials offered in the literature as suitable for active carbons (23), was used as non porous standard.

Pore size distributions (PSDs) from the nitrogen adsorption data were obtained through the application of non local density functional theory (NLDFT) procedure (24) using a software provided by the Micromeritics Instrument Corporation. The NLDFT method for deriving PSDs is based on the assumption that experimental isotherms can be expressed as the sum of contributions from ideal isotherms calculated for adsorbate molecules on pores of fixed shape and size, the weighing function being equivalent to the PSD. Fluid-fluid interactions are accounted for using one-center Lennard-Jones potentials. The pores are modeled as an array of semi-infinite, rigid slits and their walls as 
energetically uniform graphite. An analogous NLDFT method implemented for carbon dioxide (25), provided by Quantachrome, was used to obtain PSDs from the $\mathrm{CO}_{2}$ adsorption data.

The accessible surface areas of the samples based on immersion calorimetry data were determined with the method proposed by Denoyel et al. (26), using as a reference the areal enthalpies of immersion of Vulcan $3\left(S_{B E T}=82 \mathrm{~m}^{2} \mathrm{~g}^{-1}\right)$.

\section{Results and Discussion}

\subsection{Nitrogen adsorption isotherms, comparative plots and derived PSDs. Fig. 1} shows the high resolution $\mathrm{N}_{2}$ adsorption isotherms obtained for the samples under study. The adsorption isotherm of the pyrolyzed sample was not included in this figure because this material has a very narrow porosity, which is not accessible to $\mathrm{N}_{2}$ at $77 \mathrm{~K}$. As for the remaining samples, all their isotherms belong to type I according to the IUPAC classification (27), although distinctions can be established between them based on the widening of their knee as the burn-off increases. Whereas the isotherms of the low burn-off samples exhibit quite a sharp knee, reflecting the predominance of narrow microporosity (ultramicropores, i. e., pores with widths smaller than $0.7-0.8 \mathrm{~nm}$ ), those corresponding to high burn-off degrees have a more rounded knee pointing to a widening of microporosity that even extends to mesoporosity in the sample activated to the highest burn-off, as shown by the appearance of a very narrow hysteresis loop in its isotherm.

To take full advantage of the information provided by the high resolution isotherm, the isotherms are represented on a semilogarithmic scale, as shown in Fig. 1b. Sing (21b) and Kaneko (22) pointed out that the pore filling process could be divided into three or 

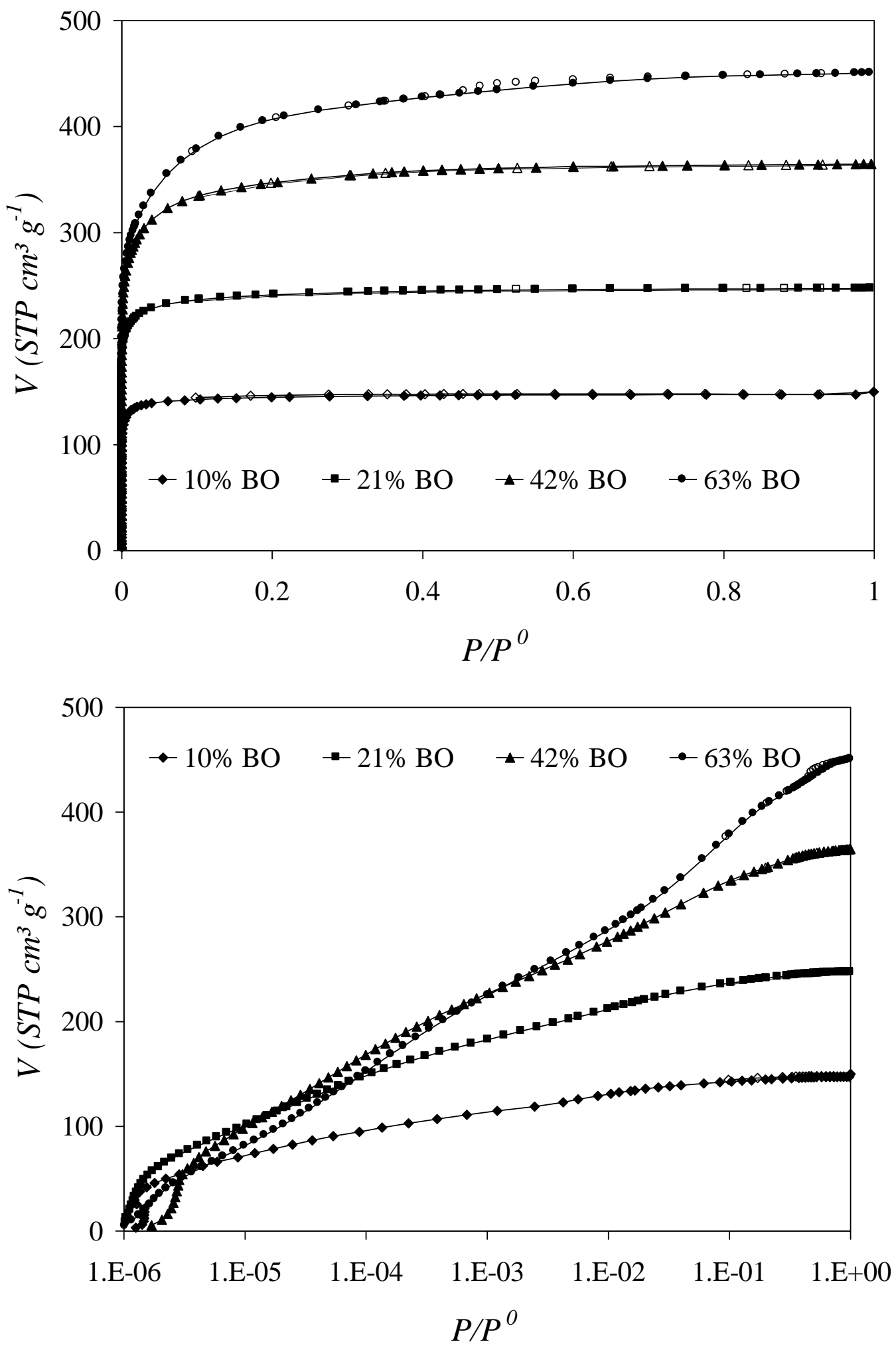

Figure 1. Adsorption-desorption isotherms of $\mathrm{N}_{2}$ at $77 \mathrm{~K}$. Filled symbols, adsorption; empty symbols, desorption. (a) Conventional plots; (b) Semilogarithmic scale 
four stages: the filling of narrow micropores (ultramicropores), monolayer formation on the wider micropores (supermicropores) and small mesopores, the filling of mesopores by capillary condensation, and the filling of macropores by capillary condensation, which can be ascribed, respectively, to relative pressure ranges of ca. $10^{-6}-10^{-4}, 10^{-4}-10^{-2}, 10^{-2}-10^{-1}$, and 0.9-1. Unlike conventional activated carbons (28) but like other ACFs (20, 29), all the samples in this work, even those activated to the highest BO, show a significant nitrogen uptake below $p / p^{0}=10^{-5}$, indicating the presence of a large amount of ultramicropores. However, the relative importance of the narrowest microporosity in the total porosity of the samples diminishes as $\mathrm{BO}$ increases. While ACFs activated to low BOs $(10 \%, 21 \%)$ adsorb a large percentage of their total nitrogen uptake below $p / p^{0}=10^{-4}$, the uptake at the relative pressure range related to supermicropores $\left(10^{-4}-10^{-2}\right)$ acquires significance for the ACFs activated to higher BOs $(42 \%, 63 \%)$, and even the appearance of a small amount of mesoporosity in the sample activated to $63 \% \mathrm{BO}$ is reflected in the corresponding pressure range in its isotherm.

BET surface areas, $S_{B E T}$, and total pore volumes, $V_{p(N 2)}$, for the activated samples are given in Table 1. It can be seen that they increase systematically with the degree of burn-off over the range covered by this series. The very low relative pressures from which BET plots show linearity $\left(\sim 10^{-6}-10^{-5}\right)$ for all the samples are an indication of the highly microporous nature of their texture (30).

Table 1. Textural parameters derived from $\mathrm{N}_{2}$ adsorption at $77 \mathrm{~K}$.

\begin{tabular}{|c|c|c|c|c|c|c|}
\hline \multirow[t]{2}{*}{$\% \mathrm{BO}$} & \multirow[t]{2}{*}{$\begin{array}{c}S_{B E T} \\
\left(\mathrm{~m}^{2} \mathrm{~g}^{-1}\right)\end{array}$} & \multirow[t]{2}{*}{$\begin{array}{c}V_{p(N 2)} \\
\left(\mathrm{cm}^{3} \mathrm{~g}^{-1}\right)\end{array}$} & \multicolumn{4}{|c|}{$\alpha_{S}$ method } \\
\hline & & & $\begin{array}{l}S_{\text {ext }}(\alpha s, N 2) \\
\left(\mathrm{m}^{2} \mathrm{~g}^{-1}\right)\end{array}$ & $\begin{array}{l}V_{\mu p(\alpha s, N 2)} \\
\left(\mathrm{cm}^{3} \mathrm{~g}^{-1}\right)\end{array}$ & $\begin{array}{l}V_{\text {uцp }(\alpha s, N 2)} \\
\left(\mathrm{cm}^{3} \mathrm{~g}^{-1}\right)\end{array}$ & $V_{u \mu p(\alpha s, N 2)} / V_{\mu p(\alpha s, N 2)}$ \\
\hline 10 & 560 & 0.23 & 0.2 & 0.23 & 0.13 & 0.56 \\
\hline 21 & 936 & 0.38 & 1.5 & 0.38 & 0.20 & 0.53 \\
\hline 42 & 1329 & 0.56 & 2.7 & 0.56 & 0.18 & 0.32 \\
\hline 63 & 1580 & 0.69 & 12.3 & 0.68 & 0.11 & 0.17 \\
\hline
\end{tabular}


Regarding the $\alpha_{S}$ plot analysis, Kaneko et al. (22) found that microporous carbons could show two upward swings from linearity below the downward bending due to saturated filling at higher $\alpha_{S}$, which they designated as filling swing (FS) and cooperative swing (CS), corresponding to $\alpha_{S}$ smaller and greater than 0.5, respectively. Both upward swings come from enhanced adsorbent-adsorbate interactions as a function of the pore size, and can be ascribed to different types of filling: primary micropore filling, which takes place in micropores whose width is less than two adsorbate molecular diameters, i.e., around $0.7-0.8 \mathrm{~nm}$ (ultramicropores (31)), for FS and cooperative adsorption in larger micropores (supermicropores) for CS.

The $\alpha_{S}$ plots derived from the $\mathrm{N}_{2}$ adsorption data can be seen in Fig. 2. The two samples activated to the lowest BOs show mainly FS in the $0<\alpha_{S}<0.5$ range, with little evidence for CS, further confirming the view that ultramicropores are the dominant pores in these samples. On the other hand, the presence of both FS $\left(0<\alpha_{S}<0.5\right)$ and CS $(0.5<$ $\alpha_{S}<1$ ), in the two samples activated to the highest BOs is evidence of the existence of both ultramicropores and supermicropores. As burn-off increases, the FS, although still present, becomes less pronounced.

The textural parameters deduced from the application of the $\alpha_{S}$ method ( $S_{\text {ext }} \alpha s$, $\left.\left.{ }_{N 2}\right), V_{\mu p(\alpha s, N 2)}, V_{u \mu p(\alpha s, N 2)}\right)$ are given in Table 1. A comparison of $V_{p(N 2)}$ and $V_{\mu p(\alpha s, N 2)}$ shows that both parameters follow the same rising trend with increasing burn off. These values coincide in all samples as might be expected given that most of their porosity is restricted to microporosity. The very small discrepancy for the sample with the highest $\mathrm{BO}(63 \%)$ indicates that mesoporosity is barely developed, as mentioned above. A quantitative estimate of the relative importance of the ultramicroporosity in the microporosity of the ACFs studied can be made from the ratio between $V_{u \mu p(\alpha s, N 2))}$ and $V_{\mu p(\alpha s, N 2)}$ given in Table 1. The progressive weakening of the FS with increasing burn-off is reflected in the 


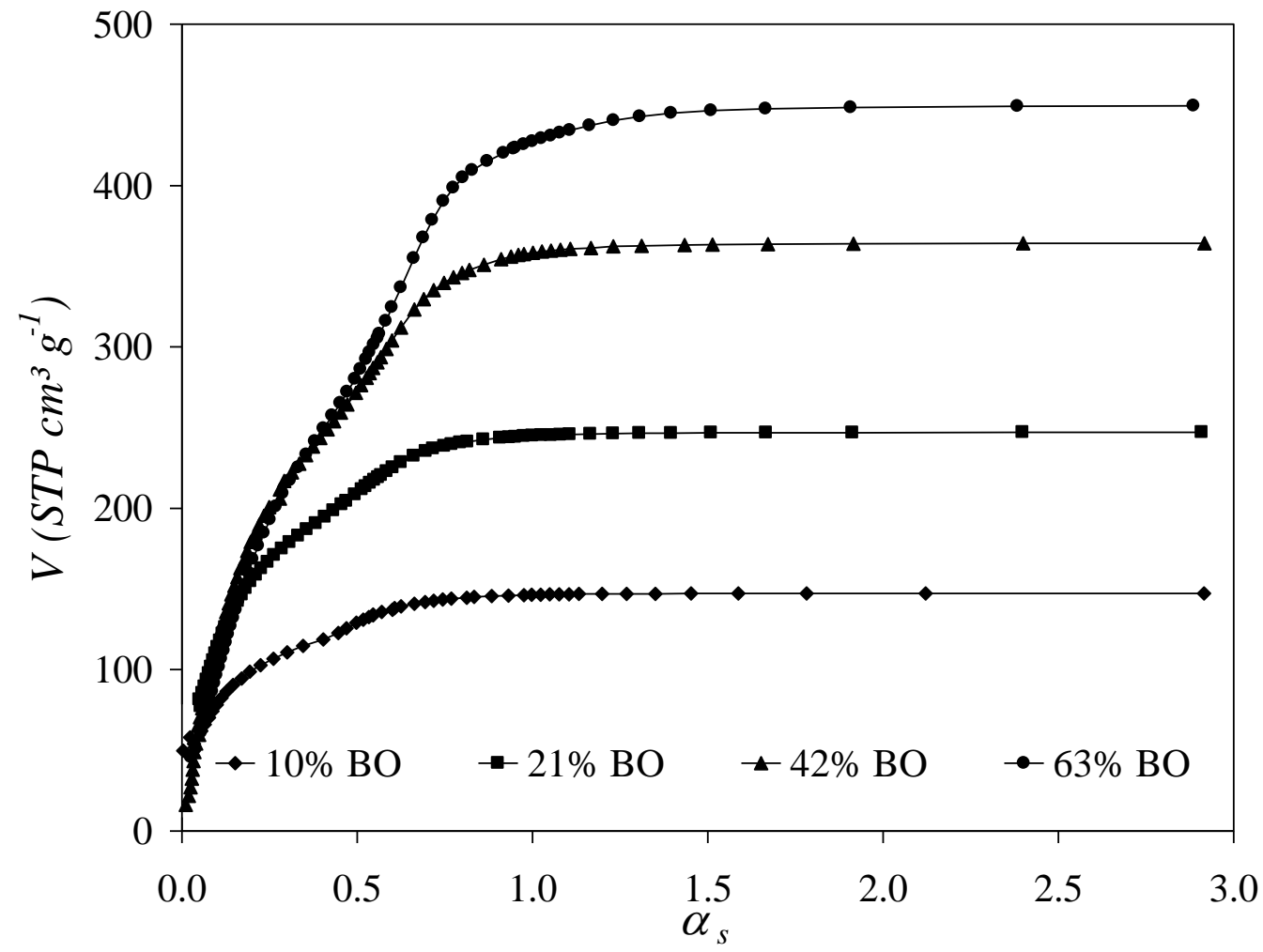

Figure 2. $\alpha_{\mathrm{S}}$ plots drawn from $\mathrm{N}_{2}$ adsorption isotherms for the series of activated carbon fibers.

decreasing value of this ratio. The low value found for the sample activated to the highest $\mathrm{BO}$ again indicates that porosity has significantly widened in this sample.

As regards the PSDs, NLDFT distributions for all samples (Fig. 3) present maxima at around $0.6 \mathrm{~nm}$ with pore sizes under 1.6, 2.0, 3.2 and $7.0 \mathrm{~nm}$, respectively, for the samples arranged in an increasing burn-off sequence. The PSDs reflect a widening in the micropore size distribution. This takes place in a restricted pore size range below $2.0 \mathrm{~nm}$, i.e. in the microporosity range, for all the samples except the one activated at $63 \% \mathrm{BO}$.

However, it is known that the NLDFT method is not totally reliable as a tool for yielding PSDs as it has model-induced artifacts (31). The rigid parallel wall model used to build the theoretical adsorption isotherms exhibits strong packing effects which are not 
present in real activated carbons. As a consequence, the resulting pore size distributions consistently show two minima at around 0.6 and $1 \mathrm{~nm}$, corresponding to the transitions from pore widths accommodating one adsorbed layer to two, and two layers to three, respectively. This feature is confirmed in Fig. 3.

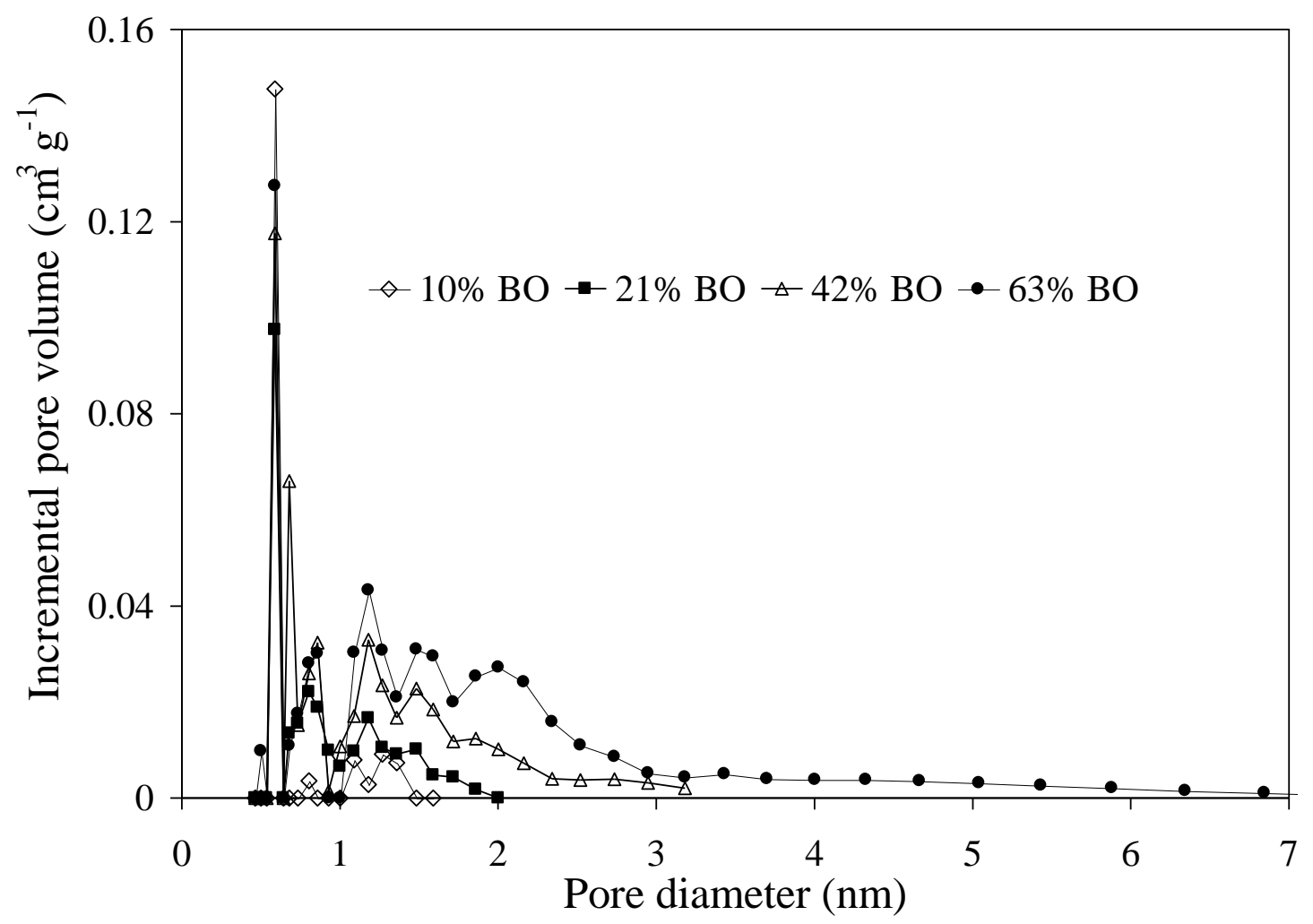

Figure 3. PSDs obtained from the $\mathrm{N}_{2}$ adsorption isotherms through application of the NLDFT method.

\subsection{Carbon dioxide isotherms, Dubinin-Radushkevich plots and derived PSDs.}

Carbon dioxide at $273 \mathrm{~K}$ and at subatmospheric pressures is known to cover only the microporosity range from around $0.3 \mathrm{~nm}$ to about $1.4 \mathrm{~nm}(25)$. On the other hand, a lower cut-off pore width of around $0.4 \mathrm{~nm}$ is generally assumed for nitrogen adsorption at $77 \mathrm{~K}$ owing to restricted diffusion. Thus, it has been suggested that the adsorption of these two 
molecules should be used in a complementary way in order to characterize micro and mesoporosity more fully (33).

Fig. 4 shows the $\mathrm{CO}_{2}$ adsorption isotherms for pyrolyzed and steam activated Nomex. Although the characterization by nitrogen adsorption at $77 \mathrm{~K}$ of the pyrolyzed sample was not possible, $\mathrm{CO}_{2}$ adsorption at a higher temperature $(273 \mathrm{~K})$ serves as a useful tool for samples with narrow microporosity such as this one. At the early stages of activation, the $\mathrm{CO}_{2}$ uptake increases over the entire relative pressure range covered, as can be confirmed by comparing the isotherms for the pyrolyzed and 10\% BO activated samples. Although the total uptake at $P / P^{0}=0.03$ increases upon activation, a decrease in the uptake at low pressures is observed for further activated samples, reflecting the disappearance of some of the narrowest microporosity. Finally, the sample activated at the highest burn off even evidences a decrease in $\mathrm{CO}_{2}$ total uptake, probably because high degrees of activation lead to the elimination of some of the pore walls in narrow micropores, thereby decreasing the amount of micropores enclosed in the range covered in these conditions.

The Dubinin-Radushkevich (DR) plots and textural parameters such as micropore volume $\left(V_{\mu p(D R, C O 2)}\right)$ and adsorption energy $E_{0}$, calculated through the application of the DR equation to $\mathrm{CO}_{2}$ adsorption data, are shown in Fig. 5 and Table 2 respectively. Straight lines typical of microporous solids were obtained. The plot is linear over the whole range of relative pressures measured for the pyrolysed sample as well as for that activated to $10 \% \mathrm{BO}$. The fact that the former required longer times to reach equilibrium reflects a certain molecular restriction to the access of $\mathrm{CO}_{2}$ to the pores in these conditions. The range of linearity decreases for the rest of the samples. In fact, the sample activated to $63 \%$ BO shows two linear branches from which two different values of $V_{\mu p(D R, C O 2)}$ could have been calculated. This is further confirmation of the widening of micropore size distribution as the burn-off increases, resulting in different filling mechanisms for 


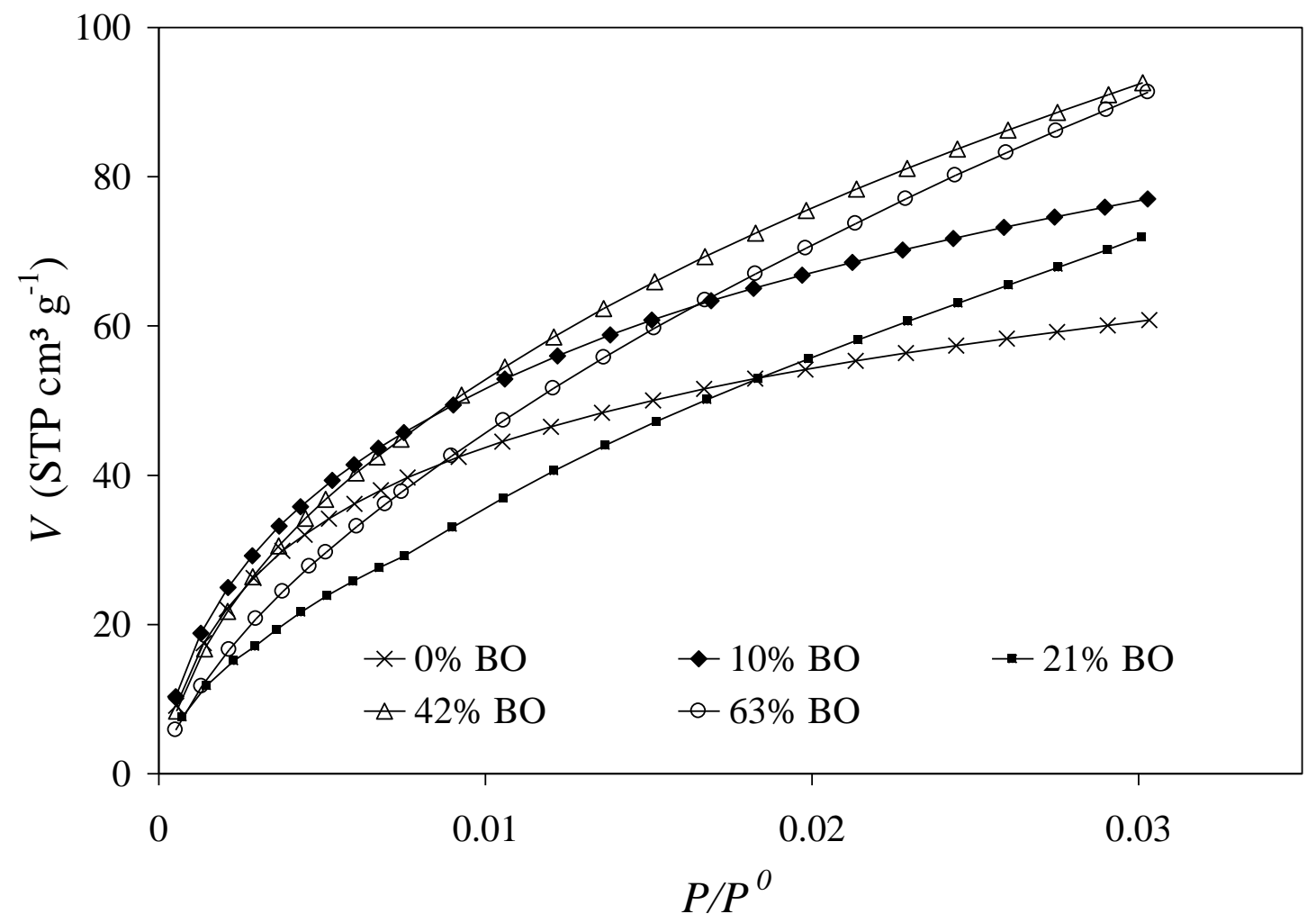

Figure 4. Adsorption isotherms of $\mathrm{CO}_{2}$ at $273 \mathrm{~K}$ on carbonized Nomex and ACFs prepared from it by steam activation.

micropores of different size. Concerning the trends for the different parameters derived

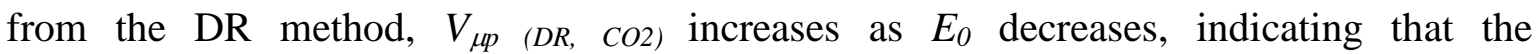
microporosity range covered, (ultramicroporosity), develops through the widening of the pores. However, the nitrogen adsorption data suggested that the development of microporosity as a whole in Nomex-derived ACFs mainly involves the creation of new micropores and/or the deepening of pre-existing ones, widening being a relatively minor contribution in comparison with ACFs derived from other precursors. It must been taken into account that nitrogen adsorption covers a wider range of porosity than carbon dioxide, thus offering a more general picture of textural evolution. 


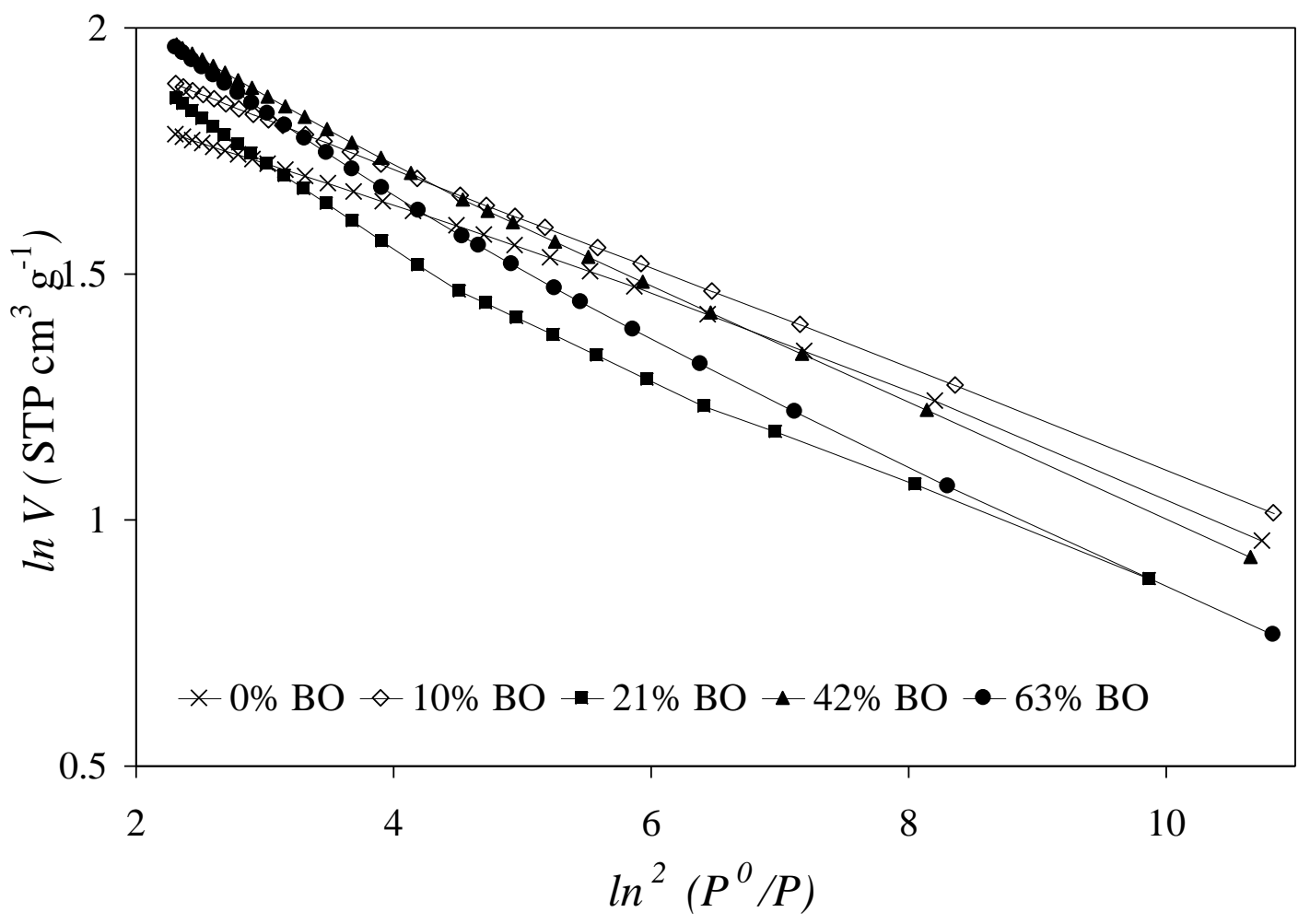

Figure 5. DR plots obtained from the $\mathrm{CO}_{2}$ adsorption data.

Table 2 Textural parameters calculated through the application of the DR equation to $\mathrm{CO}_{2}$ adsorption data at $273 \mathrm{~K}$.

\begin{tabular}{ccc}
\hline$\% \mathrm{BO}$ & \multicolumn{2}{c}{ DR method } \\
\cline { 2 - 3 } & $\begin{array}{c}V_{\mu p(D R, C O 2)} \\
\left(\mathrm{cm}^{3} \mathrm{~g}^{-1}\right)\end{array}$ & $\begin{array}{c}E_{0} \\
\left(\mathrm{KJ} \mathrm{mol}^{-1}\right)\end{array}$ \\
\hline 0 & 0.16 & 27.5 \\
10 & 0.22 & 25.7 \\
21 & 0.26 & 20.7 \\
42 & 0.29 & 23.1 \\
63 & 0.38 & 19.5 \\
\hline
\end{tabular}


The comparison of $V_{\mu p}(\alpha s, N 2)$ determined by $\mathrm{N}_{2}$ adsorption (through the $\alpha_{S}$ method) with $V_{\mu p}$ (DR, CO2) determined by $\mathrm{CO}_{2}$ adsorption (through the $\mathrm{DR}$ method) can provide useful information about the texture of the samples (32). The already discussed results from applying the $\square \alpha_{S}$ method to $\mathrm{N}_{2}$ adsorption were found to be equivalent to those derived from the application of the DR method to the same data (not shown to avoid

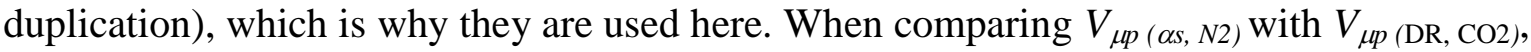
three different situations typically arise as pores widen. The first situation, in which $V_{\mu p}$ (os, $\left.{ }_{N 2}\right)<V_{\mu p}$ (DR, CO2), appears for the pyrolyzed sample. This situation usually occurs in molecular sieve carbons, carbonized materials or activated carbons with a very low burnoff (30). If, as already mentioned, carbon dioxide adsorption in these conditions starts from the smallest pore widths, around $0.3 \mathrm{~nm}$, while nitrogen adsorption is restricted to pores wider than $0.4 \mathrm{~nm}$, the volume of micropores with widths between 0.3 and $0.4 \mathrm{~nm}$ can be

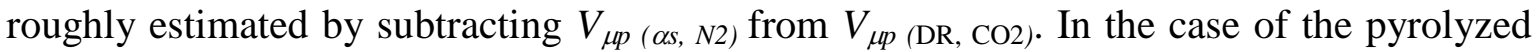
sample studied in this work, no nitrogen at all was adsorbed, i. e., $V_{\mu p(\alpha s, N 2)}=0$, reflecting the fact that all the pores belong to the pore width interval, which is optimum for the separation of gas mixtures such as $\mathrm{CO}_{2}(0.33 \mathrm{~nm}) / \mathrm{CH}_{4}(0.38 \mathrm{~nm})$ and $\mathrm{O}_{2}(0.346$ $\mathrm{nm}) / \mathrm{N}_{2}(0.364 \mathrm{~nm})(14)$. Consequently, the pyrolyzed sample could in principle serve as a good molecular sieve, al least from the point of view of selectivity. The usual argument against the use of simply pyrolyzed carbonaceous materials as molecular sieves is their low adsorption capacity. However, this is not the case here, as the micropore volume of the sample $\left(V_{\mu p(D R, C O 2)}=0.16 \mathrm{~cm}^{3} \mathrm{~g}^{-1}\right)$ is well inside the range of those exhibited by commercial and non-commercial carbon molecular sieves in the literature $(34,35)$. Moreover, the densities used in the literature for $\mathrm{CO}_{2}$ adsorbed at $273 \mathrm{~K}$ are typically lower than the one used in this work and consequently the values calculated for micropore volumes are "inflated" in relation with ours. 
The second situation, $V_{\mu p(\alpha s, N 2) \sim} V_{\mu p}$ (DR, CO2), arises for the sample activated to $10 \%$ $\mathrm{BO}$ and is the usual situation for some molecular sieves and activated carbons with a low or intermediate burn-off. As micropore volumes derived from nitrogen and carbon dioxide adsorption isotherms are practically identical for the $10 \%$ BO sample, all the porosity is restricted to microporosity, as in the first situation, but in this case the pores must have widened. If there are any pores left in the 0.3-0.4 $\mathrm{nm}$ range, only filled by $\mathrm{CO}_{2}$ adsorption, in order that both volumes become equal, some development of microporosity must have occurred beyond the pore widths of $1.4 \mathrm{~nm}$, covered exclusively by $\mathrm{N}_{2}$.

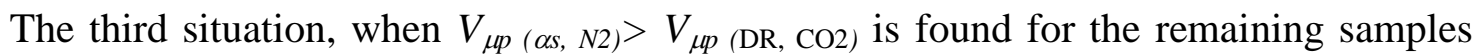
and implies the continued development of porosity beyond the upper limit of $1.4 \mathrm{~nm}$ covered by $\mathrm{CO}_{2}$ adsorption. This is typical of activated carbons with a relatively high burnoff.

As for the possible use of the activated samples studied in this work, their rather small and uniform pore sizes make them promising CMS precursors through carbon chemical vapor deposition (36). Nevertheless, the sample activated to the highest burn-off shows mainly wide micropores, as shown above by the low $V_{u \mu p}(\alpha s, N 2)$ to $V_{\mu p(\alpha s, N 2)}$ ratio, which even extends to mesopores (from the small hysteresis loop found in its isotherm). This makes its possible application even as a precursor of carbon molecular sieves doubtful. Moreover, such a high burn-off is hardly admissible from a practical point of view due to excessive carbon consumption.

Incremental pore volume plots calculated from $\mathrm{CO}_{2}$ adsorption (NLDFT method) for all the samples are shown in Fig. 6. As the calculation procedure is analogous to that applied to nitrogen adsorption data, an artificial minimum at around $0.6-0.7 \mathrm{~nm}$, related to the ideal transition from one to two layers of adsorbate, is also found systematically. The next transition from two to three layers is not appreciated in the relative pressure range 
extending to atmospheric pressure (25). The PSDs are represented up to the limit of sensitivity of $\mathrm{CO}_{2}$ adsorption, in these conditions fixed at $1 \mathrm{~nm}$, as theoretical isotherms for solids with pores greater than $1 \mathrm{~nm}$ are linearly dependent and, consequently, these pores cannot be distinguished.

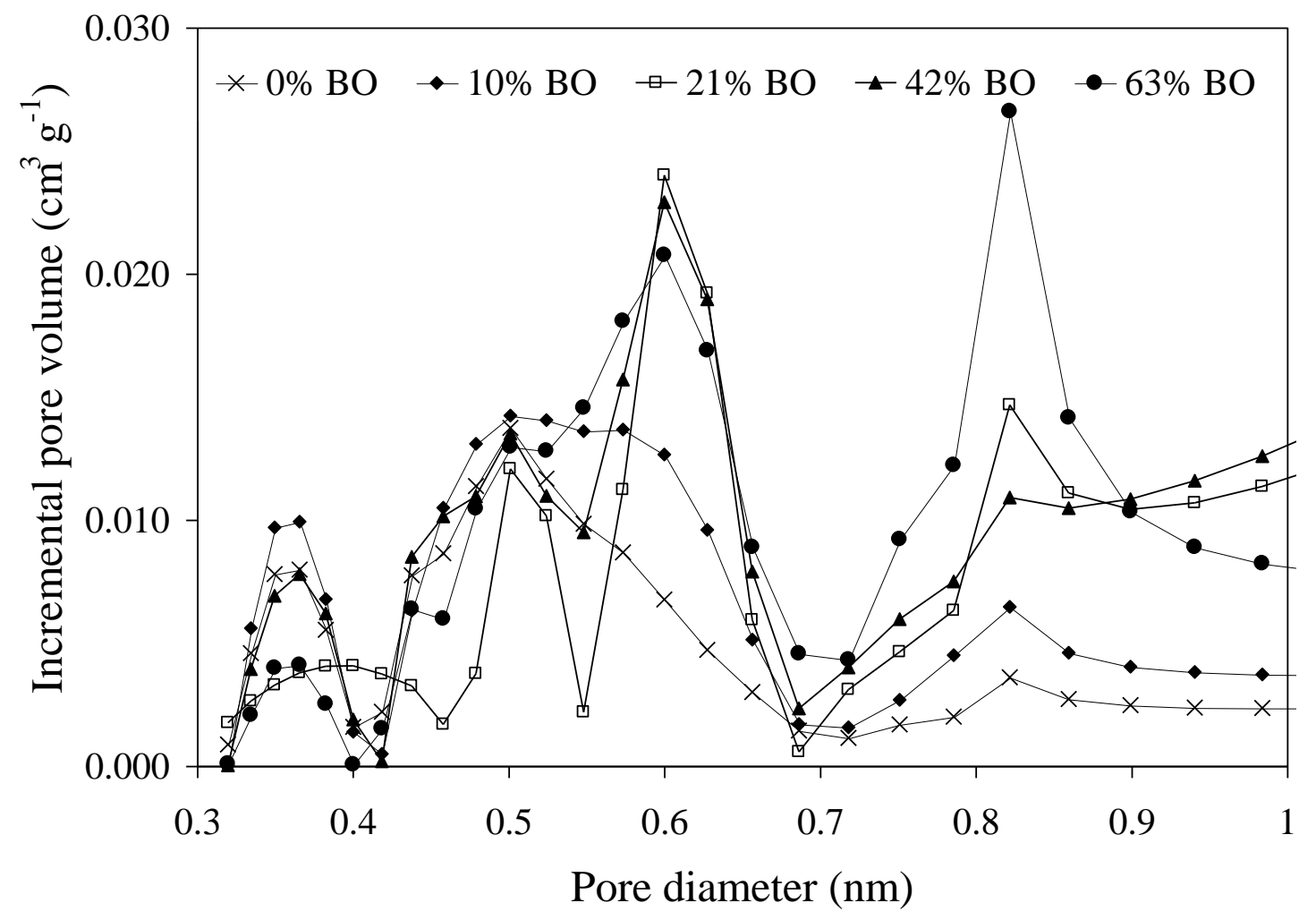

Figure 6. PSDs obtained from the $\mathrm{CO}_{2}$ adsorption isotherms through application of the NLDFT method.

As can be seen in Fig. 6, the pyrolyzed sample shows maxima at 0.35 and $0.50 \mathrm{~nm}$ which are also present in the activated samples. But as burn-off increases, the former disappears while the latter is gradually hidden, already at $10 \% \mathrm{BO}$, by the appearance of another maximum at $0.6 \mathrm{~nm}$. For the most activated samples, the maximum for the PSDs occurs at $0.82 \mathrm{~nm}$. Consequently, in the porosity range covered by $\mathrm{CO}_{2}$ adsorption, widening of the pores can also be appreciated, as samples would have maxima for their 
PSDs at around 0.35 and $0.50 \mathrm{~nm}(0 \% \mathrm{BO}), 0.50-0.60 \mathrm{~nm}(10 \% \mathrm{BO}), 0.60 \mathrm{~nm}(21 \%$ and $42 \% \mathrm{BO})$ and $0.82 \mathrm{~nm}(63 \% \mathrm{BO})$.

4.3. Immersion calorimetry measurements. As calculation methods based on data from a single isotherm do not seem to be totally reliable, it was thought advisable to employ adsorptive molecules of different sizes as molecular probes to assess the different stages of micropore filling in a direct way (37) through immersion calorimetry experiments.

A comparison of the different proportionality factors between the heats of immersion and surface areas obtained for a number of reference materials is given in Table 3. As can be seen, the values of specific surface areas derived from immersion data may vary significantly depending on the choice of the reference material. For example, the surface area of a material derived from its heat of immersion into $\mathrm{C}_{6} \mathrm{H}_{6}$ using Spheron 6 would be almost twice the value obtained using Reference1. As Spheron 6 is an extreme case, with the highest ratio of heat of immersion to surface area, Vulcan 3 was finally chosen as the reference to calculate specific surface areas derived from the immersion calorimetry data measured in this work.

Table 4 shows the experimental enthalpies of immersion in the various organic liquids studied of all the samples except for the one activated to the highest burn-off together with the calculated accessible surface areas. This sample (63\% BO) was useful for setting an upper limit for developing of exclusively microporosity through activation, but it has been excluded from further analysis because it is not of interest for possible application as a molecular sieve carbon.

The samples activated to low BOs (0 and $10 \%$ BO) show surface areas accessible to dichloromethane higher than those accessible to benzene. However, the rest of the 
samples show the opposite trend. This change in the activation series could be explained in terms of an evolution of the surface chemistry of the pyrolyzed sample, as activation takes place by way of the loss of surface functional groups, the appetence for polar molecules such as dichloromethane decreasing. Nevertheless, generally speaking, chemical factors are not thought to be important in an adsorption process like this $(11,40,41)$.

Table 3. Ratios between the enthalpy of immersion at $298 \mathrm{~K}$ into the three liquids used in this work and the BET surface area for different reference materials.

\begin{tabular}{|c|c|c|c|c|}
\hline & \multicolumn{4}{|c|}{ Ratio $\left(\mathrm{mJ} \mathrm{m}^{-2}\right)$} \\
\hline & $\begin{array}{c}\text { Reference } 1^{\mathrm{a}} \\
\left(50 \mathrm{~m}^{2} \mathrm{~g}^{-1}\right)\end{array}$ & $\begin{array}{l}\text { Vulcan 3G b } \\
\left(62 \mathrm{~m}^{2} \mathrm{~g}^{-1}\right) \\
\end{array}$ & $\begin{array}{l}\text { Vulcan } 3^{\mathrm{c}} \\
\left(82 \mathrm{~m}^{2} \mathrm{~g}^{-1}\right)\end{array}$ & $\begin{array}{l}\text { Spheron } 6^{c} \\
\left(108 \mathrm{~m}^{2} \mathrm{~g}^{-1}\right)\end{array}$ \\
\hline $\mathrm{CH}_{2} \mathrm{Cl}_{2}$ & 63 & 113 & 134 & 170 \\
\hline $\mathrm{C}_{6} \mathrm{H}_{6}$ & 76 & 114 & 111 & 148 \\
\hline $\mathrm{C}_{6} \mathrm{H}_{12}$ & 60 & 104 & 104 & 101 \\
\hline
\end{tabular}

${ }^{a}$ Calculated from data in ref. 38.

${ }^{\mathrm{b}}$ Calculated from data in ref. 39 .

${ }^{\mathrm{c}}$ This work.

Table 4. Experimental enthalpies of immersion at $298 \mathrm{~K}$ into different liquids and surface areas derived from them and from $\mathrm{N}_{2}$ adsorption at $77 \mathrm{~K}$.

\begin{tabular}{|c|ccc|ccc|c|}
\hline \multirow{2}{*}{$\%$ BO } & \multicolumn{3}{|c|}{$-\Delta H_{\text {imm }}\left(\mathrm{J} \mathrm{g}^{-1}\right)$} & \multicolumn{3}{c|}{ Surface areas $\left(\mathrm{m}^{2} \mathrm{~g}^{-1}\right)$} & \multirow{2}{*}{$S_{B E T}\left(\mathrm{~m}^{2} \mathrm{~g}^{-1}\right)$} \\
\cline { 2 - 6 } & $\mathrm{CH}_{2} \mathrm{Cl}_{2}$ & $\mathrm{C}_{6} \mathrm{H}_{6}$ & $\mathrm{C}_{6} \mathrm{H}_{12}$ & $\mathrm{CH}_{2} \mathrm{Cl}_{2}$ & $\mathrm{C}_{6} \mathrm{H}_{6}$ & $\mathrm{C}_{6} \mathrm{H}_{12}$ & \\
\hline 0 & 45.3 & 11.0 & 10.0 & 338 & 100 & 96 & $-^{\mathrm{a}}$ \\
10 & 92.1 & 65.9 & 47.6 & 687 & 600 & 460 & 560 \\
21 & 123.1 & 122.4 & 81.6 & 918 & 1116 & 787 & 936 \\
42 & 138.1 & 146.7 & 107.6 & 1029 & 1337 & 1038 & 1329 \\
\hline
\end{tabular}

${ }^{a}$ Only geometrical surface 
Surface areas accessible to benzene are systematically higher than the corresponding BET surface areas. As the minimal dimensions of nitrogen $(0.36 \mathrm{~nm})$ and benzene $(0.37 \mathrm{~nm})$ are nearly the same, both molecules should have access to similar microporosity ranges. It has been asserted (26) that differences such as this arise from the underestimation of the actual surface area of microporous carbons whose pores have widths similar to one adsorbate molecule by the calculation of BET surface area. This underestimation occurs because one molecule is only considered to be in contact with only one planar surface. In the immersion method, the interaction of the molecule with both walls of the pore is taken into account giving higher, more realistic values. Accordingly, the biggest differences between the surface areas derived from nitrogen and benzene adsorption would appear in the samples with the narrowest porosities that are accessible to both molecules. This trend can be verified in the series studied as the differences between the two surface areas decrease with increasing burn-off, differences barely being noticeable in the sample activated to $42 \%$ BO. It was previously shown in discussing parameters calculated by the $\alpha_{S}$ method that the contribution of ultramicropores to the microporosity of this sample is smaller than for the samples activated to lower BOs. At $42 \% \mathrm{BO}$, the microporosity has widened to the point that almost all the pores can accommodate more than one molecule of nitrogen, so that the hypothesis of the BET surface is acceptable in this case.

For the next probe molecule, cyclohexane, the values for accessible surface areas are lower than the BET surface areas for all the samples except the pyrolyzed one, indicating a molecular sieve effect. The different sizes of nitrogen $(0.36 \mathrm{~nm})$ and cyclohexane $(0.48 \mathrm{~nm})$ molecules justify the differences as the bigger molecules will have access to a smaller range of microporosity in the samples. However, for the pyrolyzed sample, the surface area accessible to cyclohexane is higher than the BET surface area 
(assuming this to be the geometrical area). The porosity in this sample is probably so narrow that the leading factor is the underestimation of the area calculated from $\mathrm{N}_{2}$ adsorption which, at $77 \mathrm{~K}$, has restricted diffusion limitations in the pores of molecular dimensions. As a result, the difference in the size of the two molecules is counterbalanced.

\section{Summary}

It can be deduced from the different analyses performed that the microporosity developed in the samples studied through activation is mainly restricted to pores between one and two molecular diameters (of $\mathrm{N}_{2}$ or $\mathrm{C}_{6} \mathrm{H}_{6}$ ), i. e. ultramicropores. Nevertheless, there is a qualitative change between the two samples activated to lower burn-offs ( 0 and $10 \%)$ and the other samples. Ultramicropores are the dominant micropores in the former while supermicropores gain significance in the latter.

The absolute values for specific surface areas derived from immersion calorimetry measurements are highly dependent on the reference material chosen. This must be taken into account when comparing with other values in the literature or with BET $\left(\mathrm{N}_{2}\right)$ surface areas.

\section{Acknowledgements}

The authors wish to thank their colleagues Javier Fernández and Celina Blanco (DuPont Asturias) for providing the Nomex sample. Financial support from CICYT (Project 1FD1997-1915) is gratefully acknowledged. We also acknowledge a predoctoral fellowship from the Spanish Ministry of Education awarded to S.V.-R., which allowed her to carry out a stay at MADIREL (CNRS-Université de Provence). 


\section{References}

(1) Bansal, C. R., Donnet, J. B. and Stoeckli F., “Active Carbon.” Marcel Dekker, New York, 1988.

(2) Derbyshire, F., Jagtoyen, M., Andrews, R., Rao, A., Martín-Gullón, I. and Grulke, E.A., "Carbon materials in environmental applications" in "Chemistry and Physics of Carbon”, (L. R. Radovic., Ed.), vol. 27, pp. 1-66. Marcel Dekker, New York, 2001.

(3) Freeman, J. J., Tomlinson, J. B., Sing, K. S. W. and Theocharis, C. R., Carbon 6, 865 (1993).

(4) Freeman, J. J., Tomlinson, J. B., Sing, K. S. W. and Theocharis, C. R., Carbon 33, 795 (1995).

(5) Matsumoto, A., Zhao J. and Tsutsumi K., Langmuir 13, 496 (1997).

(6) Martínez-Alonso, A., Jamond, M., Montes-Morán, M. A. and Tascón, J. M. D., Microporous Mater. 11, 303 (1997).

(7) Blanco López, M., Villar-Rodil, S. M., Martínez-Alonso, A. and Tascón, J. M. D., Microporous Mesoporous Mater. 41, 319 (2000).

(8) Mosquera, M. E. G., Jamond, M., Martínez-Alonso, A. and Tascón, J. M. D., Chem. Mater. 6, 1918 (1994).

(9) Villar-Rodil, S. M., Martínez-Alonso, A. and Tascón, J. M. D., J. Anal. Appl. Pyrolysis 58-59, 105 (2001).

(10) Villar-Rodil, S. M., Paredes, J. I., Martínez-Alonso, A. and Tascón, J. M. D., Chem. Mater. 13, 4297 (2001).

(11) Stoeckli, F., Centeno, T.A., Fuertes, A. B. and Muñiz, J., Carbon 34, 1201 (1996).

(12) Blanco López, M.C., Martínez-Alonso, A. and Tascón, J. M. D., Microporous Mesoporous Mater. 34, 171 (2000). 
(13) Blanco López, M.C., Martínez-Alonso, A. and Tascón, J. M. D., Carbon 38, 1173 (2000).

(14) Freeman, J. J., Gimblett, F. G., Hayes, R. A., Amin, Z. M. and Sing, K. S. W. in “Characterization of Porous Solids II" (F. Rodríguez-Reinoso et al., Eds.), p. 366. Elsevier, Amsterdam, 1991.

(15) Ryu, S. K., Jin, H., Gondy, D., Pusset, N. and Ehrburger, P., Carbon 31, 841 (1993).

(16) Molina-Sabio, M., González, M. T., Rodríguez-Reinoso, F. and Sepúlveda-Escribano, A., Carbon 34, 505 (1996).

(17) Silvestre-Albero, J., Gómez de Salazar, C., Sepúlveda-Escribano, A. and RodríguezReinoso, F., Colloids Surf. A 187-188, 151 (2001).

(18) Partyka, S., Rouquerol, F. and Rouquerol, J., J. Colloid Interface Sci. 68, 21 (1979).

(19) Cascarini de Torre, L. E., Bottani, E. J. and Steele, W. A., Langmuir 12, 5399 (1996).

(20) Ryu, Z., Zheng, J., Wang, M. and Zhang, B., J. Colloid Interface Sci. 230, 312 (2000).

(21) Gregg, S. J. and Sing, K. S. W., “Adsorption, Surface area and Porosity.” (a) p. 94, (b) p. 242. Academic Press, London, 1982.

(22) Kaneko, K., Ishii, C., Ruike, M. and Kuwabara, H., Carbon 30, 1075 (1992).

(23) Setoyama, N., Suzuki, T. and Kaneko, K., Carbon 36, 1459 (1998).

(24) Olivier, J. P., Conkin, W. P. B. and Szombathely, M. V. in "Characterization of Porous Solids III” (J. Rouquerol, F. Rodríguez-Reinoso, K. S. W. Sing and K. K. Unger, Eds.), p.81. Elsevier, Amsterdam, 1994.

(25) Vishnyakov, A., Ravikovitch, P. I. and Neimark, A. V., Langmuir 15, 8736 (1999).

(26) Denoyel, R., Fernandez-Colinas, J., Grillet, Y. and Rouquerol, J., Langmuir 9, 515 (1993). 
(27) Sing, K. S. W., Everett, D. H., Haul, R. A. W., Moscou, L., Pieriotti, R. A., Rouquerol, J. and Siemieniewska, T., Pure Appl. Chem. 57, 603 (1985).

(28) Dombrowski, R. J., Hyduke, D. R., Lastoskie, C. M., Langmuir, 16, 5041 (2000).

(29) Li, Z., Kruk, M., Jaroniec, M., Ryu, S. K., J. Colloid Interface Sci. 204, 151 (1998).

(30) Rouquerol, F., Rouquerol, J. and Imelik, B., Bull. Soc. Chim. Fr. 635 (1964).

(31) Dubinin, M. M., Prog. Surf. Membrane Sci. 9, 1 (1975).

(32) Olivier, J. P., Carbon 36, 469 (1998).

(33) Garrido, J., Linares-Solano, A., Martín-Martínez, J. M., Molina-Sabio, M., RodríguezReinoso, F. and Torregrosa, R., Langmuir 3, 76 (1987).

(34) De la Casa-Lillo, M. A., Alcañiz-Monge, J., Raymundo-Piñero, E., Cazorla-Amorós, D. and Linares-Solano, A., Carbon 36, 1353 (1998).

(35) Reid, C. R., O’Koye, I. P. and Thomas K. M., Langmuir 14, 2415 (1998).

(36) Freitas, M. M. A. and Figueiredo, J. L., Fuel 80, 1 (2001).

(37) Sing, K. S. W., Adv. Colloid Interface Sci. 76-77, 3 ( 1998).

(38) Manso, R., "Preparación de tamices moleculares de carbono a partir de carbones minerales”, Salamanca, Spain: University of Salamanca, 1999, Ph. D. Thesis.

(39) Gómez-de-Salazar, C., "Desarrollo de tamices moleculares de carbón para la separación de mezclas de gases", Alicante, Spain: University of Alicante, 2000, Ph. D. Thesis. 